\title{
Complicated migraine resulting in blindness due to bilateral retinal infarction
}

\author{
Andrew M Glenn, Pamela J Shaw, John W Howe, David Bates
}

\begin{abstract}
Retinal migraine is not uncommon, but permanent sequelae in the anterior visual pathway are rare. We describe the case of a young woman in whom blindness developed over a six-year period due to recurrent episodes of migrainerelated occlusions of a branch retinal artery.
\end{abstract}

Migraine occurs in $10-25 \%$ of the population ${ }^{1}$ and is more common in women than in men. 'Complicated migraine' occurs in $1 \%$ of cases and is defined as an episode of classical migraine which results in a persisting neurological deficit. ${ }^{2}$ Persisting visual morbidity in migraineurs is usually caused by posterior cerebral hemisphere ischaemia. ${ }^{3}$ Permanent anterior visual pathway damage related to migraine has been reported rarely. Several types of migraine-related retinal vascular lesions have been described, including branch retinal artery occlusion (BRAO),${ }^{4-8}$ central retinal artery occlusion, ${ }^{47-11}$ ciliary artery occlusion, ${ }^{12}$ anterior ischaemic optic neuropathy, ${ }^{13-15}$ and central retinal vein thrombosis. ${ }^{12} 16$ Other retinal abnormalities described as migraine related include; optic nerve haemorrhage, ${ }^{17}$ disc oedema and retinal haemorrhage, ${ }^{18}$ inner retinal layer damage, ${ }^{19}$ optic atrophy, ${ }^{4}$ and neuroretinitis. ${ }^{4}$

We report a case of a young woman who had recurrent attacks of migraine-related BRAO affecting both eyes and resulting in legal blindness

\section{Case report}

A 20-year-old housewife began experiencing classical migraine at the age of 14 years. She was initially treated with propranolol as a prophylactic agent. At the age of 15 in association with a typical migraine attack she developed profound and persisting loss of vision in the left eye. The visual actuity of the affected eye was reduced to perception of light, and only the superotemporal quadrant of vision remained intact. Funduscopy revealed an acute occlusion of the superotemporal, superonasal, and inferotemporal arteries. The left sided visual loss persisted despite treatment with acetazolamide, amyl nitrate, and $\mathrm{CO}_{2}$ rebreathing.

Eight months later, following an increase in the frequency of her migraine, she developed an occlusion of a macular branch of the right superotemporal arteriole which resulted in a permanent scotoma and a reduction of visual acuity on the right to $6 / 9$.

At the age of 20 , again following an increase in the frequency of her migraine, she suddenly developed further loss of vision in the right eye due to an inferotemporal BRAO affecting the macula (Fig 1). On this occasion she was treated with the calcium channel blocker nimodipine and intravenous methyl prednisolone $1 \mathrm{~g}$ daily for three days. No visual recovery occurred.

The patient had not been taking an oral contraceptive agent and had never been prescribed ergot derivatives. Her father, brother, and niece also suffer from migraine.

\section{EXAMINATION}

A general medical examination revealed no significant abnormalities. In particular she was normotensive, the heart was clinically normal, and there were no carotid or orbital bruits. Slitlamp examination revealed normal anterior segments, and the intraocular pressures were $14 \mathrm{~mm}$ $\mathrm{Hg}$ in both eyes. After the most recent BRAO her visual acuity was counting fingers in the right eye and hand movements in the left. There was loss of the central and superotemporal visual field of the right eye and loss of all but the superotemporal quadrant of the left. Funduscopy showed an acute occlusion of the inferotemporal arteriole on the right and optic atrophy plus attenuation of the superior and inferior temporal arterioles on the left. A fluorescein angiogram, performed on the right eye two days after the inferior temporal BRAO (Fig 2) showed occlusion of the inferotemporal arteriole and evidence of the previous superior macular branch arteriolar occlusion.

\section{INVESTIGATIONS}

The following investigations gave normal or negative results: full blood count, erythrocyte sedimentation rate, routine biochemical screen-

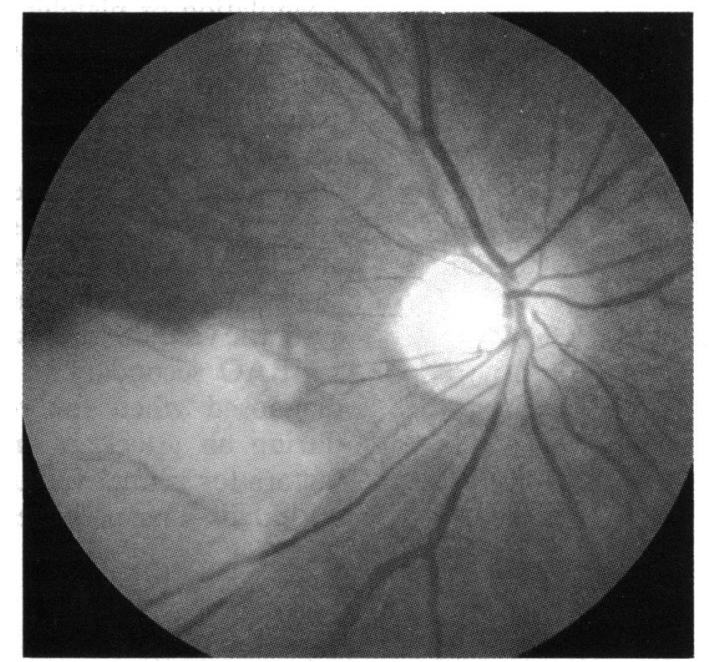

Figure 1 Photograph of the right fundus showing occlusion of the inferior temporal arteriole and atrophy of the superior temporal disc corresponding to the previous macular branch occlusion. 
Figure 2 Fluorescein angiogram of the right eye showing occlusions of the inferotemporal and superior macular branch arterioles.

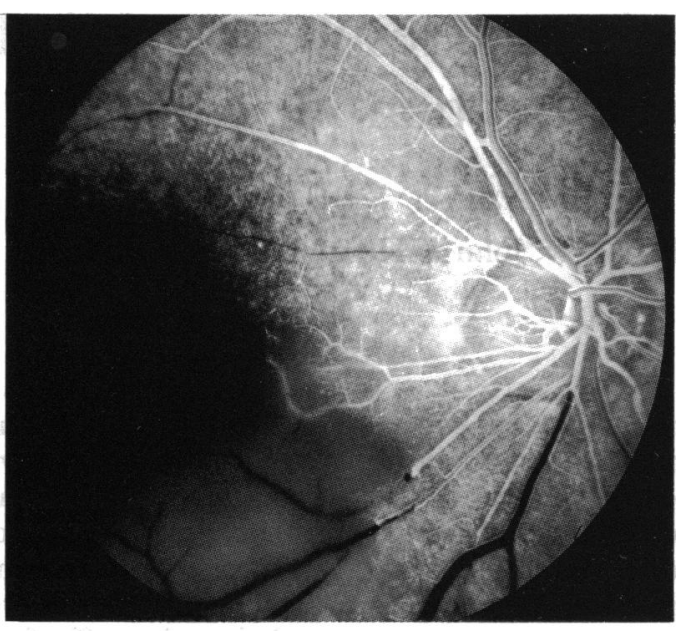

ing tests, VDLR/TPHA, autoantibodies including anticardiolipin antibodies and DNA binding, fasting blood lactate and pyruvate and lactate/ pyruvate ratio, serum angiotensin converting enzyme, full clotting studies including prothrombin time, activated partial thromboplastin time, platelet function studies, protein $\mathrm{C}$, protein $\mathrm{S}$, levels of factors $\mathrm{V}$ and VIII and lupus anticoagulant, fasting cholesterol, and triglycerides. A chest radiograph and electrocardiograph were normal, and $\mathrm{M}$-mode and two dimensional echocardiography gave normal findings, with no evidence of a cardiac embolic source. A cranial CT scan was normal and the cerebrospinal fluid showed normal levels of protein, IgG, glucose, and cells. A Colour Flow Duplex Scan (an ultrasound and doppler haemodynamic study) revealed normal flow and morphology in the carotid arteries.

\section{Discussion}

In the elderly BRAO is usually due to emboli from atheroma at the carotid bifurcation. ${ }^{2021}$ In younger patients systemic disorders associated with retinal vasculitis, such as sarcoidosis and collagen vascular disease, may lead to BRAO. ${ }^{22}$

In a series of 27 cases of retinal artery occlusion occurring under the age of 30 years risk factors were identified in the majority and included coagulation or platelet disorders, heart disease, or the use of oral contraceptive agents. ${ }^{5}$ Migraine was the sole risk factor for retinal stroke in only two (7\%). Gass et $a l^{23}$ recently reported on a series of nine patients (age range 24-69 years) with idiopathic recurrent BRAO. The fundal appearances were suggestive of focal arteritis and arteriolitis. Most of these patients retained good central vision, and none developed evidence of systemic vascular disease.

BRAO secondary to retinal migraine can be diagnosed when the retinal infarction occurs during an attack of migraine and other risk factors for retinal vascular occlusion have been excluded. The pathogenesis of retinal vascular occlusion in migraine is incompletely understood. The most widely accepted theory is that there is an episodic reduction in retinal blood flow, due to vasospasm and/or vessel wall oedema. ${ }^{24}$ This may be associated with a thrombotic predilection because of abnormalities of platelets, plasma, and/or blood vessels. ${ }^{25}$

In our case after episodes of BRAO vasodilators, calcium channel blockers, intravenous steroids, and measures to reduce intraocular pressure were ineffective in ameliorating the visual loss. Furthermore antimigraine prophylaxis with $B$ blockers and serotonin antagonists did not prevent further attacks. The usefulness of antiplatelet agents, particularly for prevention of migraine related infarcts, requires evaluation. There is recent animal experimental evidence that glutamate antagonists given after cerebrovascular occlusion may reduce the area of cerebrovascular damage. ${ }^{26}$ Such agents may be of value in limiting the area of infarcts following retinal vascular occlusions.

1 Waters WE, O'Conner PS. Prevalence of migraine. 7 Neurol

Neurosurg Psychiatry 1975; 38: 613-6.
2 Pearce JMS, Foster JB. An investigation of complicated migraine. F Neurol Sci 1965; 15: 333-40.

3 Broderick JP, Swanson JW. Migraine-related strokes. Clinical profiles and prognosis in 20 patients. Arch Neurol 1987; 44: profiles

4 Galezowski X. Ophthalmic megrim. Lancet 1882; i: 176-7. Brown GC, Magargal LE, Shield JA, Goldberg RE, Walsh PN. Retinal artery obstruction in children and young adults Ophthalmology 1981; 88: 18-25.

6 Gronvall $\mathrm{H}$. On changes in the fundus oculi and persisting injuries to the eye in migraine. Acta Ophthalmol (Kbh) 1983 16: $602-11$.

7 Graveson GS. Retinal artery occlusion in migraine. BMF 1949; ii: $838-40$.

8 Pearce J The ophthalmological complications of migraine. $\mathcal{F}$ Neurol Sci 1968; 6: 73-81.

9 Walsh FB. Clinical neuro-ophthalmology. Baltimore: Williams and Wilkins, 1947.

$10 \mathrm{Krapin} \mathrm{D}$. Occlusion of the central retinal artery in migraine. NEngl f Med 1964; 270: 359-60

11 Katz B Migrainous central retinal artery occlusion. 7 Clin Neuro Ophthalmol 1986; 6: 69-70.

12 Coppeto JR, Lessel S, Sciarra R, Bear L. Vascular retinopathy in migraine. Neurology 1986; 36: 267-70.

$13 \mathrm{Katz}$ B. Bilateral sequential migrainous ischemic optic neuropathy. Am $\mathcal{F}$ Ophthalmol 1985; 99: 489.

14 Weinstein JM, Feman SS. Ischemic optic neuropathy in migraine. Arch Ophthalmol 1982; 100: 1097-100.

15 Katz B. Migrainous ischemic optic neuropathy. Neurology 1985; 35: 112-14

16 Friedman MW. Occlusion of the central retinal vein in migraine. Arch Ophthalmol 1951; 45: 678-82.

17 Gaynes PM, Towle PA. Haemorrhage in hyaline bodies (drusen) of the optic disc during an attack of migraine. $A m \mathcal{F}$ Ophthalmol 1967; 63: 1693-6.

18 Victor DI, Welch RB. Bilateral retinal hemorrhages and disk edema in migraine. Am 7 Ophthalmol 1977; 84: 555-8.

19 Dubois LG, Sadun AA, Lawton TB. Inner retinal layer loss in complicated migraine. Case report. Arch Ophthalmol 1988; 06: $1035-7$

20 Kollarits CR, Lubow M, Hissang SL. Retinal strokes. I Incidence of carotid atheroma. $\mathscr{F} A M A$ 1972; 222: 1273-5

21 Heges TR, Giliberti Ol, Magargal LE. Intravenous digita subtraction angiography and its role in ocular vascular disease. Arch Ophthalmol 1985; 103: 666-9.

22 Haskjold E, Froland S, Egge K. Ocular polyarteritis nodosa: report of a case. Acta Ophthalmol (Kbh) 1987; 65: 749 .

23 Gass JDM, Tiedeman J, Thomas MA Idiopathic recurren branch retinal artery occlusion. Ophthalmology 1986; 93 : $1148-57$.

24 Featherstone $\mathrm{HJ}$. Clinical features of stroke in migraine: a review. Headache 1986; 26: 128-35.

25 Kalendovsky Z, Austin JH. Complicated migraine: its association with increased platelet aggregability and abnormal plasma coagulability factors. Headache 1975; 15: 18-35.

26 Albers GW, Goldberg M, Choi DW. NMDA antagonists in brain ischemia. Ann Neurol 1989; 25: 398-403. 